\title{
Comparison of Particle Dispersion Strengthening Estimated by Orowan Model and Ashby-Orowan Model
}

\author{
Setsuo TAKAKI ${ }^{1)}$ and Masahiro TSUKAHARA ${ }^{1)^{*}}$ \\ 1) Neturen Co., Ltd.
}

Abstract: In the steels with different particle dispersion, particle dispersion strengthening $\Delta \sigma$ was theoretically estimated by Orowan model and Ashby-Orowan model. The comparison of experimental data with theoretical values proved the reasonability of Orowan model rather than Ashby-Orowan model. In Ashby-Orowan model, the line tension coefficient of dislocation is evaluated much smaller and this leads to the under-estimation of $\Delta \sigma$. It was also confirmed that there is no effect of grain size on $0.2 \%$ proof stress of the steels used. As a result, it is concluded that the yield stress of steels with finely dispersed particle can be explained by the addition of friction stress and particle dispersion strengthening, in the case the grain size is sufficiently larger than the particle dispersion spacing.

Keywords: strengthening mechanism; particle dispersion strengthening; Orowan model; Ashby-Orowan model; mean free path; grain refinement strengthening.

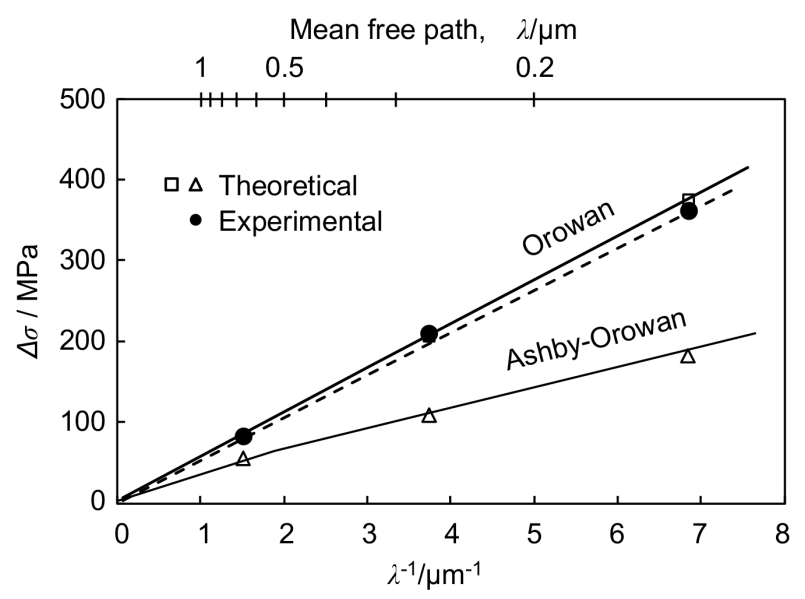




\section{Orowan model ならびにAshby- Orowan modelで見積もられた 粒子分散強化の比較}

\author{
高木 節雄 ${ }^{1)}$. 塚原 真宏 ${ }^{1) *}$
}

Comparison of Particle Dispersion Strengthening Estimated by Orowan Model and Ashby-Orowan Model Setsuo TAKAKI and Masahiro TsuKahara

\section{1. 緒言}

金属材料の強化という点では, 粒子分散強化は最も簡便 で効果的な手法である。幸い, 鉄鋼材料では, 炭素の固溶 限が高温相のオーステナイトで大きく, 低温相のフェライ トで極端に小さいという特長を利用して, 炭化物の析出を 利用して材料を強化できる。セメンタイト $\left(\mathrm{Fe}_{3} \mathrm{C}\right)$ は, 鉄鋼 材料において代表的な炭化物であるが, 炭化物としては軟 質な方である ${ }^{1)}$ 。せん断強度が低い粒子を微細に分散させ ると粒子が転位でせん断されてしまい，十分な延性が得ら れないため, 析出強化で高い強度を求める場合, $\mathrm{VC}$ や $\mathrm{NbC}$ などのせん断強度が高い粒子を分散させる必要がある。分 散粒子が転位でせん断されないような状況では，すべり面 上の転位は粒子を迂回して運動せねばならず，粒子間で転 位が張り出すのに必要な応力が粒子分散強化量に対応する (粒子迂回メカニズム)。しかし, 粒子迂回メカニズムにつ いては, Orowan モデル ${ }^{2)}$ と Ashby-Orowan モデル ${ }^{3)}$ のつの 考え方が提案されており, 粒子分散強化の議論に打いて混 乱を招くことが懸念される。そこで本稿では, 粒子の分散 状態が大きく異なる 3 種類の試料を用いて, 理論的に求め た強化量と実験值を比較することによって2つのモデルの 妥当性を検証した。さらに, 結晶粒微細化強化と粒子分散 強化の関係についても検討した。

\section{2. 使用した鋼における組織と機械的特性}

本研究では, 粒子の分散状態が大きく異なる試料とし て, $\mathrm{Fe}_{3} \mathrm{C}, \mathrm{VC}, \mathrm{TiO}_{2}$ を分散させた 3 種類の鋼を用いた。そ れぞれ, $\mathrm{Fe}_{3} \mathrm{C}$ 鋼, $\mathrm{VC}$ 鋼, $\mathrm{TiO}_{2}$ 鋼ということにする。 $\mathrm{Fe}_{3} \mathrm{C}$ 鋼 は加工したマルテンサイトに $700^{\circ} \mathrm{C} て ゙ 10 \mathrm{~h}$ の焼戻しを施
し，基地を再結晶させてフェライトにしている。 $\mathrm{VC}$ 鋼は $\mathrm{VC}$ 析出させたマルテンサイトを $(\gamma+\mathrm{VC})$ 二相域に再 加熱し，その温度から炉冷して基地をフェライトにしてい る。 $\mathrm{TiO}_{2}$ 鋼は, メカニカルミリング処理した $\left(\right.$ 鉄 $\left.+\mathrm{TiO}_{2}\right)$ 粉 をステンレスパイプに真空封入し, $700{ }^{\circ} \mathrm{C} て ゙$ 固化成形したバ ルク体を $1000^{\circ} \mathrm{C} に$ 再加熱し, そのあと空冷するという熱処 理で基地をフェライトにした。それぞれの鋼で分散粒子は 異なっているが, いずれも球状の粒子がフェライト基地中 に均一に分散した組織となっていることを確認した ${ }^{4,5}$ 。詳 細な製造法や熱処理については原論文を参照していただき たい。分散粒子が転位でせん断される Cutting メカニズムで は強化量が分散粒子の性質で変化するが, 粒子迂回メカニ ズムについては分散粒子の性質は強化量に影響しない。使 用した材料について, 化学成分, 化学成分から見積もられ た摩擦力 $\sigma_{0}{ }^{6}$, 引張試験で得られた $0.2 \%$ 耐力 $\sigma_{0.2}$, フェライ 卜粒径 $D$, 分散粒子の体積割合 $f$ をまめて Table 1 に示す。

鋼中に分散した粒子は透過型電子顕微鏡を用いて観察 し, 粒子の直径を計測した。測定した粒子の粒度分布を Fig.1に示す。粒度分布は, $\mathrm{Fe}_{3} \mathrm{C}$ 鋼については過時効が起こ る条件で焼戻しを行っているために正規分布に近い形に なっているが, 他の 2 鋼種については対数正規分布を呈し ている。粒子の計測数については, 粒子の計測数を増やし ながら後述の方法で平均自由行程 $\lambda$ を計算し, $\lambda$ 值が一定 の值に収束することでその妥当性を確認した。なお, 本研 究で使用した分散粒子のビッカース硬さ ${ }^{1,7)}$ ならびに転位 でせん断できる最大粒子径 (臨界粒子径; $\left.d_{c}\right)^{6}$ を Table 2 に 示す。 $\mathrm{TiO}_{2}$ のビッカース硬さについてはモース硬度》を変 換したもので, $d_{c}$ の值は硬さから見積もられた概算値であ

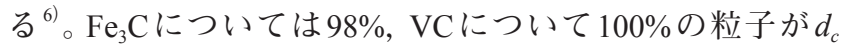
より大きく, 転位と粒子の相互作用が粒子迁回メカニズム であることを確認できる。ただし $\mathrm{TiO}_{2}$ については, 約 $50 \%$ の粒子は $20 \mathrm{~nm}$ 以下の大きさであり, これらの粒子につい てはCuttingメカニズムが働いている可能性を否定できな い。Cutting メカニズムの場合, 粒子径が小さいほど強化へ の寄与は小さくなるが, 粒子径が $d_{c} に$ 近いものについては 粒子迂回メカニズムと同程度の強化量が得られることが分 かっているあ。

\section{OrowanモデルとAshby-Orowan モデルに おける転位の線張力係数}

転位の線張力 $T$ は, 転位の線張力係数 $\beta$, 剛性率 $G$, 転位 のBurgersベクトル $b$ の関数として次式で与えられる。フェ

Table 1. Chemical composition (mass \%), friction stress $\sigma_{0}, 0.2 \%$ proof stress $\sigma_{0.2}$, ferrite grain size $D$ and volume fraction of precipitates $f$ in the steels used.

\begin{tabular}{c|cccccc||c|c|c|c|c}
\hline Steel & $\mathrm{C}$ & $\mathrm{Si}$ & $\mathrm{Mn}$ & $\mathrm{Ni}$ & $\mathrm{Cr}$ & $\mathrm{V}$ (Solute $\mathrm{V})$ & $\sigma_{0}[\mathrm{MPa}]$ & $\sigma_{0.2}[\mathrm{MPa}]$ & $\mathrm{D}[\mu \mathrm{m}]$ & $f$ \\
\hline $\mathrm{Fe}_{3} \mathrm{C}$ & 0.16 & 0.45 & 0.47 & 0.5 & 0.4 & 0 & 173 & 256 & 20 & 0.0245 \\
\hline $\mathrm{VC}$ & 0.194 & 0.08 & 0.09 & 0 & 0 & $0.96(0.14)$ & 71 & 280 & 21 & 0.0136 \\
\hline $\mathrm{TiO}_{2}$ & 0 & 0.18 & 0.45 & 0 & 0 & 0 & 105 & 467 & 60 & 0.05 \\
\hline
\end{tabular}


ライト鋼については, $G=80.6 \mathrm{GPa}, b=0.2482 \mathrm{~nm}$ である。

$$
T[N]=\beta G b^{2}
$$

ここで, 転位の線張力係数 $\beta$ は, 転位芯の半径 $r_{0}$, 転位の 応力場の半径 $r$, 転位の性質に依存した定数 $k$ の関数として 次式で与えられる。

$$
\beta=\left\{\ln \left(r / r_{0}\right)\right\} /(4 \pi k) \ldots
$$

定数 $k$ にいては，ポアソン比を $v($ 鉄 : 0.29) とすると, 刃状転位で $k=1-v ， ら$ せ転位で $k=1$ ，一般的な混合転位 では両者の中間の值を採って $k \fallingdotseq 0.85$ と見做して良い。転 位芯の半径 $r_{0}$ につては $2 b$ 程度の值と考えて良いであろ $う^{3)}$ 。転位の応力場の大きさ $r$ については, Orowan モデル では分散粒子の大きさとは無関係にほぼ一定と仮定して おり，100nm 程度の值を式 (1) に代入して $\beta=0.5$ という值 が採用されることが多い。これに対応した転位の線張力は $2.5 \times 10^{-9}[N]$ 程度である。一方 Ashby-Orowan モデルでは, $r$ がすべり面上での分散粒子の直径 $d^{*}$ に依存して変化する と仮定し,$r=d^{*}$ と置いている。つまり, $\beta$ 值は一定ではな く, 分散粒子の大きさに依存して変化するわけである。転 位が粒子を迁回するときに粒子に加わるせん断力は $2 T$ な ので, 両モデルで求めた線張力 $2 T$ とすべり面上の粒子径 $d^{*}$ との関係を Fig.2に示す。Ashby-Orowanモデルでは, $2 T$ の
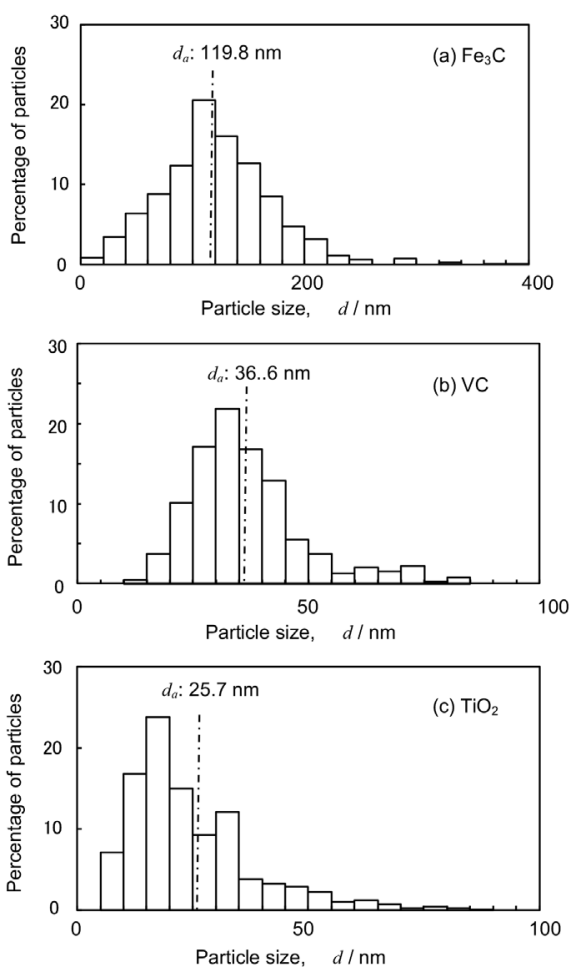

Fig. 1. Particle dispersion profile in the steels used.

Table 2. Vickers hardness $H V$ and critical particle size $d_{c}$ in particles contained in steels.

\begin{tabular}{c|c|c}
\hline Particles & $H V(\mathrm{GPa})$ & $d_{c}(\mathrm{~nm})$ \\
\hline $\mathrm{Fe}_{3} \mathrm{C}$ & 13.1 & 14 \\
$\mathrm{VC}$ & 26.5 & 7.5 \\
$\mathrm{TiO}_{2}$ & $7 \sim 11$ & $15 \sim 20$ \\
\hline
\end{tabular}

值がかなり小さく見積もられていることが分かる。罒中に は, 仮の值として粒子をせん断するのに必要なせん断力 $F_{p}$ と $d^{*}$ との関係を示している。分散粒子のせん断強度を $\tau^{*}$, 粒子内の転位の Burgers ベクトルを $b_{p}$ とすると, $F_{p}$ は $d^{*}$ の 関数として次式で与えられる。

$$
F_{p}=\tau^{*} b_{p} d^{*}
$$

$\tau^{*}$ は分散粒子の硬さに比例すると思われるので, 眓中の 破線の傾きは分散粒子が硬いほど大きくなると推察され る。粒子迂回メカニズムが起こるためには, $F_{p} \geqq 2 T$ とい う条件を満足せねばならない。Orowanモデルでは，この 条件を満足する臨界粒子径 $d_{c}$ が $F_{p}$ と $2 T$ の交点で決定され る。これに対してAshby-Orowanモデルでは, $d_{c}$ はかなり小 さな值になる。分散粒子の強度によってはすべての粒径領 域に拀いて $F_{p} \geqq 2 T$ という関係が成り立つことも考えられ， このような条件下では, “粒子がどんなに小さくなっても 転位でせん断されることはない”ということになる。この ような状況は，現実的には受け入れがたい。

\section{Orowan モデルとAshby-Orowan モデルによる 粒子分散強化の見積もり}

前述のように材料ごとに分散粒子の粒度分布は異なっ ているが, 以下に示すような統計学的手法により体積数密 度 $N\left[\right.$ 個 $\left./ \mathrm{m}^{3}\right]$ を求めることができる ${ }^{6)}$ 。実測した粒子の総 体積を $V\left[\mathrm{~m}^{3}\right]$ とすると, $1 \mathrm{~m}^{3}$ 中の炭化物の体積は $f\left[\mathrm{~m}^{3}\right]$ な

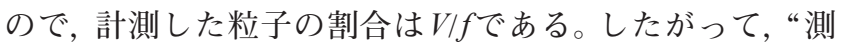
定した粒子の粒度分布が真の粒度分布を反映しているとい う”という条件が満たされている場合, 測定した粒子の数 $N_{m}$ に対して, 体積数密度 $N\left[\right.$ 個 $\left./ \mathrm{m}^{3}\right]$ は次式で与えられる。

$$
N=N_{m} \times(f / V)
$$

平均粒子径を $d_{a}$ とすると, すべり面上の分散粒子の面積 数密度 $n\left[\right.$ 個 $\left./ \mathrm{m}^{2}\right]$ は次式で与えられる ${ }^{6)}$ 。

$n=N \times d_{a}$

すべり面上の粒子の平均間隔 $L^{*}$ は, 粒子 1 個当たりの専 有面積を考慮して次式で与えられ，

$$
L^{*}=(4 / \pi)^{1 / 2} / n^{1 / 2}
$$

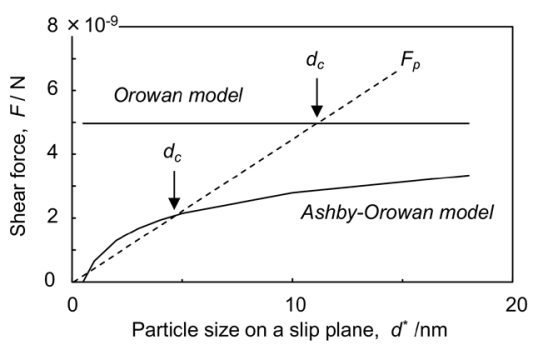

Fig. 2. Relation between particle size $d^{*}$ and the dislocation line tension $2 T$ that were estimated in Orowan model and Ashby-Orowan model (Bold lines). The shear force $F_{p}$ required to cut a particle is tentatively drawn by a broken line. 
すべり面上の粒子の平均直径 $d^{*}$ は, 体積割合 $f$ との関係 から次式で求めることができる。

$$
d^{*}=(4 f / \pi)^{1 / 2} / n^{1 / 2}
$$

したがって, 粒子間の隙間間隔に対応する平均自由行程 $\lambda$ は次式で求められる。

$$
\lambda=L^{*}-d^{*}
$$

本研究で使用した 3 鋼種について得られたこれらのパラ メーターをまとめて Table 3 に示す。 $\lambda$ の值は, 鋼種によっ て異なってはいるが $\left(\mathrm{Fe}_{3} \mathrm{C}\right.$ 鋼 $>\mathrm{VC}$ 鋼 $>\mathrm{TiO}_{2}$ 鋼)，いずれに おいても Table 1 に示したフェライト粒径に比べて十分に 小さな值である。

粒子分散強化量 $\Delta \sigma$ については, Orowan モデルの場合次 式で与えられる2)。

$$
\Delta \sigma=2 M \beta G b / \lambda
$$

ここで $M$ は多結晶金属の平均Taylor因子である。鉄 (bcc) については, $\left.M=2.75^{8}\right), \beta=0.5, G=80.6 \mathrm{GPa}, b=$ $0.248 \mathrm{~nm}$ なので，上式を簡略化した次式で $\Delta \sigma$ を見積もるこ とができる。

$$
\Delta \sigma[P a] \doteqdot 55 / \lambda
$$

一方, Ashby-Orowan モデルでは, 次式で $\Delta \sigma か ゙ 与 え ら れ る{ }^{3)}$ 。

$$
\Delta \sigma=0.8 M G b \ln \left(d^{*} / 2 b\right) /\left\{2 \pi(1-v)^{1 / 2} L^{*}\right\}
$$

Table 3のデータを基にして式（10）ならびに（11）を用 いて計算した結果を Fig.3に示す。なお図中には, Table 1 に 示した実験值から求めた $\Delta \sigma\left(=\sigma_{0.2}-\sigma_{0}\right)$ も示している。この

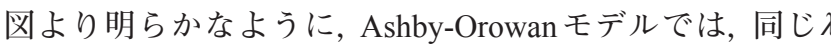
值に対して粒子分散強化量が小さな值となっている。その 原因は，前掲Fig.2で示したように，線張力係数を小さく見 積もつているところにある。実験值については，Orowan モ デルによって求めた理論值にほぼ対応しており，この結果 は，粒子迂回メカニズムで粒子分散強化が起こるモデルと してはOrowanモデルの方が妥当なことを示している。前 述のように, $\mathrm{TiO}_{2}$ 鋼については一部でCutting メカニズム が働いている可能性があり，その影響は強化量を低下させ る方向に働く。 $\mathrm{TiO}_{2}$ 鋼の実測值が理論值より若干低い值に なっているのはそのためかもしれない。また，鋼種によっ てフェライト粒径は異なっているが, 結晶粒径の影響は見 られない。その理由としては, 平均自由行程の值に対して 粒径が十分に大きいため，転位が粒子間を張り出す運動に 対して粒界が影響を及ぼさないためと思われる。ただし， 金属材料の強化機構については，すべての強化機構が加算
的に作用する可能性も否定できないため, 次章では粒子分 散強化と結晶粒微細化強化の関係について検討する。

\section{5. 粒子分散強化と結晶粒微細化強化の関係}

ここでは，フェライト粒径に依存した結晶粒微細化強化 分が $0.2 \%$ 耐力に含まれていると仮定して, 粒子分散強化 量を見積もることにした。フェライト鋼の結晶粒微細化強 化については, 結晶粒径 $D[\mu \mathrm{m}]$ に対して強化量 $\Delta \sigma_{g}[\mathrm{MPa}]$ が次式で与えられる ${ }^{9)}$ 。

$$
\Delta \sigma_{g}[\mathrm{MPa}]=600 / \sqrt{D}[\mu \mathrm{m}]
$$

Table 1 に示したフェライト粒径から見積もられる $\Delta \sigma_{g}$ は, $\mathrm{Fe}_{3} \mathrm{C}$ 鋼, $\mathrm{VC}$ 鋼, $\mathrm{TiO}_{2}$ 鋼に打いてそれぞれ $134 \mathrm{MPa}, 131$ $\mathrm{MPa}, 77 \mathrm{MPa}$ である。0.2\%耐力から摩擦力と結晶粒微細化 強化分を差し引いてプロットし直した結果を Fig.4に示す。 実験值は, Orowan モデルとAshby-Orowan モデルのどちら ともかけ離れた值となっており, $\mathrm{Fe}_{3} \mathrm{C}$ 鋼については粒子分 散強化量が負の值になっている。Fig.3ならびにFig.4の結 果は, 粒子の分散間隔に対して粒径が十分に大きいという 条件下では降伏応力に対して結晶粒径の影響がないことを 明確に示している。つまり，材料の降伏が粒子分散強化の 機構で起こる場合には, 降伏応力 $\sigma_{y}$ は, 摩擦力 $\sigma_{0}$ と粒子分 散強化量 $\Delta \sigma_{p}$ の和として, 次式で与えられると考えて良い。

$$
\sigma_{y}=\sigma_{0}+\Delta \sigma_{p}
$$

多結晶フェライト鋼の降伏については, 粒内に可動転位 が無い場合にのみ粒界での転位形成に起因した粒界転位降 伏が起こること，そして僅かな加工を施して粒内に可動転 位を導入すると降伏機構が粒内転位の運動に起因した粒内 転位降伏に変化することが示され, 結晶粒微細化強化と転

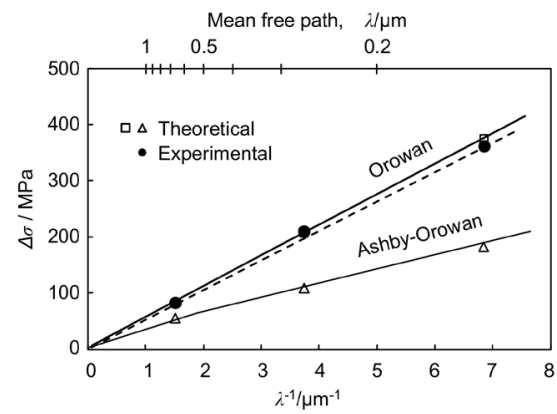

Fig. 3. Relations between mean free path $\lambda$ and increment of strength $\Delta \sigma$ that were calculated on Orowan model and Ashby-Orowan model. Experimental data were obtained by subtracting friction stress from $0.2 \%$ proof stress listed in Table 1.

Table 3. Parameters obtained by particle size measurement; The number of measured particles $N_{m}$, total volume of measured particles $V$, the number of particles in unit volume $N$, the average diameter of particles $d_{a}$, the number of particles in unit area $n$, mean particle spacing $L^{*}$, the average diameter of particles $d^{*}$ and mean free path $\lambda$ on a slip plane.

\begin{tabular}{c|c|c|c|c|c|c|c|c}
\hline Steel & $N_{m}$ & $V\left(/ \mathrm{m}^{3}\right)$ & $N\left[/ \mathrm{m}^{3}\right]$ & $d_{a}[\mathrm{~m}]$ & $n\left[/ \mathrm{m}^{2}\right]$ & $L^{*}(\mathrm{~m})$ & $d^{*}(\mathrm{~m})$ & $\lambda(\mathrm{m})$ \\
\hline $\mathrm{Fe}_{3} \mathrm{C}$ & 995 & $1.406 \times 10^{-18}$ & $1.733 \times 10^{19}$ & $1.198 \times 10^{-7}$ & $2.077 \times 10^{12}$ & $7.830 \times 10^{-7}$ & $1.226 \times 10^{-7}$ & $6.605 \times 10^{-7}$ \\
\hline $\mathrm{VC}$ & 404 & $1.444 \times 10^{-20}$ & $3.805 \times 10^{20}$ & $3.656 \times 10^{-8}$ & $1.391 \times 10^{13}$ & $3.026 \times 10^{-7}$ & $3.528 \times 10^{-8}$ & $2.673 \times 10^{-7}$ \\
\hline $\mathrm{TiO}_{2}$ & 997 & $3.581 \times 10^{-20}$ & $1.392 \times 10^{21}$ & $2.571 \times 10^{-8}$ & $3.579 \times 10^{13}$ & $1.886 \times 10^{-7}$ & $4.218 \times 10^{-8}$ & $1.464 \times 10^{-7}$ \\
\hline
\end{tabular}




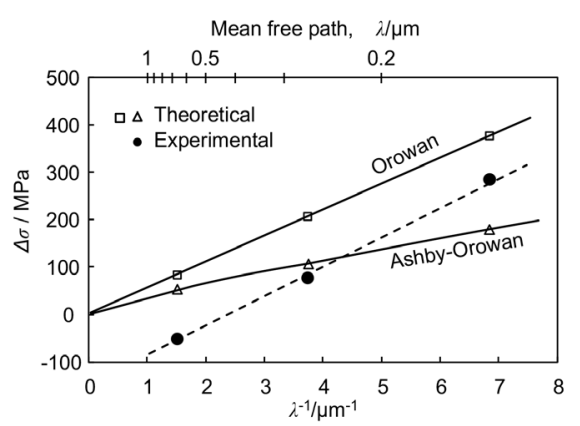

Fig. 4. Relations between mean free path $\lambda$ and increment of strength $\Delta \sigma$ that were calculated on Orowan model and Ashby-Orowan model. Experimental data were obtained by subtracting friction stress and grain refinement strengthening from $0.2 \%$ proof stress listed in Table 1 .

位強化は競合的な関係にあることが確認されている ${ }^{10)}$ 。粒 子分散強化は, すべり面上の障害物が転位ではなく分散粒 子という点が異なるだけで, 強化原理については転位強化 と同じピン止め強化であり, 粒子分散強化も転位強化と同 様に粒内転位降伏に分類される。したがって, 結晶粒微細 化強化の寄与を無視したFig.3において, Orowanモデルで 求めた理論值と実験值が合致するというのは理にかなった 結果と言えよう。ただし, 平均自由行程の値に対して粒界 の影響を無視できないほど結晶粒径が微細な場合は, 粒子 分散強化と結晶粒微細化強化の間で何らかの相互作用が働 く可能性はある。超微細粒金属の粒子分散強化については 今後の研究展開が期待されるが, 少なくとも粒子の分散間 隔に対して結晶粒が十分に大きな場合には, 粒子分散強化 に対して結晶粒径の影響は無いと言えよう。

\section{6. まとめ}

粒子迂回メカニズムによる粒子分散強化について, Ashby-Orowan モデルとOrowanモデルについてその妥当性 を検証した結果, Orowanモデルの方が妥当であるとの結 論に至った。さらに, 粒子の分散間隔に対して結晶粒が十 分に大きな場合には, 降伏応力に対して結晶粒径の影響が ないことを確認した。

\section{文献}

1 ) T.Sato, T.Nishijima and J.Ishihara: J. Jpn. Inst. Met., 23(1959), 403 (in Japanese). https://doi.org/10.2320/jinstmet1952.23.7_403

2 ) E.Orowan: Symposium on Internal Stresses in Metals and Alloys, The Institute of Metals, London (1948), 451.

3 ) M.F.Ashby: Physics of Strength and Plasticity, ed. by A. S. Argon, MIT Press, Cambridge, MA, (1969), 113-131.

4 ) T.Kitaura, H.Hidaka, T.Tsuchiyama and S.Takaki: Tetsu-to-Hagané, 91(2005), 796 (in Japanese). https://doi.org/10.2355/tetsutohagane1955. 91.11_796

5 ) M.Murakami, T.Kitaura, N.Nakada, T.Tsuchiyama and S.Takaki: Tetsu-to-Hagané, 97(2011), 152 (in Japanese). https://doi.org/10.2355/ tetsutohagane.97.152

6 ) S.Takaki: Bull. Iron Steel Inst. Jpn., 25(2020), 277 (in Japanese).

7 ) A.Fujishima: Kogaku, 29(2000), 2 (in Japanese).

8 ) G.Y.Chin and W.L.Mammel: Trans. Metall. Soc. AIME, 239(1967), 1400.

9 ) M.Etou, S.Fukushima, T.Sasaki, Y.Haraguchi, K.Miyata, M.Wakita, T.Tomida, N.Imai, M.Yoshida and Y.Okada: ISIJ Int., 48(2008), 1142. https://doi.org/10.2355/isijinternational.48.1142

10) S.Takaki: J. Jpn. Inst. Met. Mater., 83(2019), 107 (in Japanese). https:// doi.org/10.2320/jinstmet.J2018061 